\title{
Literacy and oracy across the U.S.-Mexico border: A look at the Plazas Comunitarias programme
}

\author{
Lorena Sánchez Tyson \\ UCL Institute of Education, London, UK
}

\begin{abstract}
This article explores the relationship between literacy and oracy in the context of Plazas Comunitarias, a basic education programme in Spanish for immigrants in the United States. I reflect on my experiences as a former Plazas facilitator, analyse key literacy materials from the programme and offer observations on reading aloud in an adult literacy classroom context. Additionally, I suggest that beyond facilitating overall reading development, the Plazas programme fulfils a key literacy function by fostering community building and provides access routes to community-based civil society organisations and key social institutions for immigrant groups.
\end{abstract}

Keywords: Adult education; reading aloud; literacy; oracy

\section{Introduction}

With this article, I aim to explore the concepts of literacy and oracy as interlinking units of analysis and in relation to how deeply literacy - and reading, in particular - is embedded in everyday lives, across different contexts and even across national borders. Drawing from my experiences as a facilitator for a Spanish-language basic education programme for immigrants in the United States called Plazas Comunitarias (roughly translated as 'community centre'), I discuss the programme as a whole and take a look at ways in which reading aloud is addressed in the curriculum by analysing key programme materials and offering some reflections from a facilitator's point of view. Additionally, I look at some of the wider implications of the programme in terms of community building for immigrant groups.

As a dual citizen of the U.S. and Mexico and a current doctoral student researching the meanings, values and uses of literacy within the Bilingual Literacy for Life Programme (BLLP) in Mexico (which is the indigenous language counterpart of the U.S.-based Plazas), I often reflect on my experiences of working as a Plazas facilitator in the U.S.. With this paper, I am trying to untangle theory from my practical experiences and focus on a small aspect of how educational opportunities are bridged between the two countries; namely how reading aloud pertains to adult reading development and - specific to the U.S. context - the wider functions of literacy and literacy provision for immigrant groups.

What follows is an overview of the Plazas programme and a discussion on the concepts of literacy and oracy. I then aim to provide a snapshot of reading aloud as a tool for adult literacy learning by analysing two Plazas modules that incorporate oral reading activities and discussing uses of oracy in the classroom context. Furthermore, I will reflect on the programme 
through a wider lens: beyond more formal domains of literacy and language learning, I argue that a key strength of the Plazas programme resides in its ability to connect learners with social and institutional networks through the different host organisations that enable them to participate more fully in their communities.

\section{Plazas Comunitarias}

The current discourse concerning immigration and immigrants in the U.S.- documented or otherwise - is politically fraught and has served to limit educational opportunities for immigrants, and adult immigrants in particular (Avila 2007). Meyers $(2014,7)$ posited that migration and literacy are deeply intertwined and that migration is both 'a catalyst and a complication for literacy acquisition' with complex socio-political dimensions. In this politically contested context, Mexico's National Institute for Adult Education (INEA) developed a strategy to offer educational support for the large number of Mexican immigrants living in the U.S by introducing the Plazas programme in 2001 (Hanemann 2016). The initiative was modelled on INEA's adult education programme in Mexico which has been operating since the 1990s. Since then, it has provided access routes for out-of-school adults in Mexico to gain formal qualifications from the Mexican Ministry of Education in Spanish and in over 60 indigenous languages (Délano Alonso 2018). In the U.S., the programme is overseen by the Institute for Mexicans Abroad (or IME), an agency that was created to 'empower the diaspora' of Mexican nationals living abroad (González Gutiérrez 2009; Délano Alonso 2018).

The most recent report from INEA stated that there are around 360 Plazas operating in 38 U.S. states, with over 47,000 learners enrolled (INEA 2015; Délano Alonso 2018). A network of approximately 45 Mexican consulates coordinate with regional civil society organisations to provide access to programme materials (Hanemann and Scarpino 2016). All funding for materials comes directly from the Ministry of Education in Mexico and materials are free of cost to the learners, although each host organisation may ask for discretionary fees (Hanemann 2016). INEA summarises the objective of the programme in the following way:

The Plaza meets its purpose when it becomes a place where people get together to share ideas, experiences, knowledge and to be in contact with [...] new information and communication technologies, strengthen education, culture and values of the community [...] this is why the participating institutions and groups must provide programs and resources that benefit and respond to the education or information requirements of their community (INEA n.d., 4)

Setting up a Plaza requires minimal space and equipment, mainly access to computers with internet (Jensen and Sawyer 2013). Plazas can be found in local libraries and churches, community centres and colleges, schools, workplaces, and even correctional institutions, depending on the interests and needs of each community. Currently, all materials are in Spanish and are readily available online and in print upon request by the regional consulate (Laglagaron 2010).

Plazas learners enter the programme at different levels according to the results of an initial diagnostic placement test, with emergent literacy learners learning to read and write in Spanish 
as a first step to further study (in Spanish). However, for many immigrant learners enrolled in the programme in the U.S., learning English as a Second Language (ESL) is one of the primary motivations for attending Plazas classes (Délano Alonso 2018). This was evident in the community-based non-profit organisation I worked in from 2011 to 2013, where I was one of a handful of bilingual facilitators (mostly volunteers) who worked with an average of 35 learners per week. Most of the learners were placed in the initial Spanish literacy stage; at the same time, a large number of them also enrolled separately in the ESL classes on offer within the same organisation. While the Plazas programme does not currently include any ESL materials, it is common for ESL learning opportunities to happen in parallel with (or as a result of) attending Plazas classes: in recent years, many Plazas have been advertised as a pathway for ESL learning, and there is some informational literature from INEA that makes reference to promoting basic literacy in Spanish for the benefit of learning English (INEA 2015; Délano Alonso 2018). Indeed, UNESCO's Effective Literacy and Numeracy Practices Database highlighted three examples of successful Plazas that incorporate ESL learning into their overall goals and make reference to the strong links the initiative has with ESL and GED (or high school equivalency) programmes (Hanemann 2016).

Within our small education coordination office, it was common for us to refer Plazas learners to other services under the same roof, from ESL to non-educational services including a low-cost dental clinic, a food pantry, and a clothes closet for families in need. Although the Spanish-language Plazas programme was the only one directly subsidised by the Mexican government, partner agencies such as the one I worked in often referred learners to a range of external community organisations, clinics or charities that offered different services, such as legal advice or low-cost health services. I saw how the Plazas programme acted as not just as a route to literacy and ESL, but also as a way for the learners to access and become members of different communities, whether through wider immigrant support networks or wider English-speaking communities, workplaces, schools, and more.

\section{On literacy and oracy}

Prior studies in the field of literacy have highlighted how reading and writing are fundamentally communicative acts that are strongly linked to speaking and listening (Gee 2001; HernándezZamora 2010). The term oracy is used here in an effort to conceptualise it as an equal counterpart to literacy and numeracy and broadly refers to an individual's use of speaking and listening skills to engage with the surrounding world through speech (Wilkinson 1965). Additionally, I distinguish the term emergent literacy for adults (rather than other terms such as beginner or illiterate) to indicate literacy learning that draws from prior knowledge and life experiences (Foorman 1991; Lytle 1991; Saal and Sulentic Dowell 2014).

Brandt and Clinton $(2002,348)$ argue that social practice perspectives of literacy (or literacy linked to wider social contexts, power, and identities) have helped to break down the conceptual binary between literacy and oracy and have exposed the 'complex interrelationship' between speaking, reading and writing. Furthermore, new information and communication technologies have also helped to transform prior notions of what literate practices look like and how they are conceptualised (Brandt 2001). 


\section{Reading aloud in Plazas Comunitarias}

According to Moline $(2018,86)$ reading practices in the context of adult emergent literacy classes are 'very rarely silent or personal reading', and reading aloud in particular is often seen as 'a pedagogically necessary aspect of teaching early stage reading'. This falls in line with my experiences and observations in the Plazas classroom, where every session included some form of dyadic literacy interaction involving reading aloud (learner to learner, learner to facilitator, and facilitator to learner). On a broader level, it suggests that the interdependence between oral language and literacy is particularly evident in the teaching of emergent reading for adults (Belzer 2006). Duncan and Freeman (2019) also argue that adult reading 'is so much more than a silent process of decoding text', and go on to explore different ways in which oral reading happens in everyday adult lives, within and outside of literacy learning contexts. While I can only attest to how reading aloud happened within the context of a specific Plazas classroom, my impression was that oral reading cut across different dimensions of the learners' lives as they progressed in their learning, in different ways and for different purposes. Whether it was describing how they read with their children, reading the lyrics of a song in Spanish and singing along at an end of semester celebration, reading a recipe to share with friends during class, or even describing situations such as reading their address aloud in English from a note on their refrigerator to the police during an emergency call after a suspected break-in, I gleaned from more informal interactions with Plazas learners that the reading they did was often oral and took on a larger role (in both L1 and L2) in their everyday lives as they gained more confidence with their reading.

To explore reading aloud in the context of Plazas, I decided to highlight two different modes of reading interaction that happened in the classroom for this study, one directly emerging from the Plazas curriculum and one as a result of a reflection on facilitator microadaptations at an individual learner level (Como and Snow 1986). As reading development is a core theme and a key thread that runs through the primaria (primary or elementary) and secundaria (middle or secondary) levels of the Plazas curriculum, I opted to analyse two particular modules and recall my experience as a facilitator to explore some of the ways in which the programme addresses literacy and its concomitant link to oracy in both explicit and implicit ways. By doing so, I aim to shed light both on how reading aloud is used as a tool to teach literacy in the programme as well as to think about the wider uses of reading aloud and how it is linked to oral cultures and everyday adult lives.

The modules I selected are titled Leer y escribir ('Read and write') and Hablando se entiende la gente ('Talking helps people understand each other'). Both modules are comprised of a main libro del adulto (adult's book) and several complementary materials. These main textbooks are divided into chapters that follow a theme, and incorporate activities of selfevaluation and reflection at the end of each chapter. A closer look at Leer y escribir shows several activities that engage with oral reading; for instance, there is a dramatisation exercise where the learner is asked to read lines from a short play aloud and reflect on the differences between individual, silent reading and reading aloud to a group. There is also an exercise that is based on a scenario for coordinating and speaking at a community asamblea (meeting), where the learners are tasked with interviewing some of their fellow learners to gather information about the most pressing needs of their community. Following the interviews, they 
are asked to write down the main points of what they will discuss and then read them aloud and receive feedback from the group and the facilitator on whether the ideas were communicated clearly. Because of the relatively small size of my particular Plazas classes (on average about 10 per session), the types of group reading and feedback suggested by the modules were possible and encouraged.

In the main textbook for Hablando se entiende la gente, there is an exercise that encourages the learner to reflect on when, how and with whom they would communicate through oral or written language and for what purpose. It suggests the learner ask the same questions to other people, and then write down the similarities and differences of the responses. The module also has a magazine called El poder de la palabra ('The power of the word') that features everything from recipes to traditional folk songs. In addition, there is a companion $\mathrm{CD}$, Cuando las voces se encuentran ('When voices meet each other'), that is structured like a radio programme: it has interviews, stories, and songs with the accompanying lyrics for learners to read and sing along to (including the Mexican national anthem). However, it is in the module's anthology, Asi forjamos y conservamos nuestra cultura ('This is how we forge and preserve our culture'), that the literacy-oracy link is made much clearer: this presents selected texts that are aimed at demonstrating how humans specifically use oral language to communicate their thoughts, desires and beliefs and their way of seeing the world. The subsections highlight different aspects of oral communication, including Cuando las tradiciones hablan ('When traditions speak') that discuss how the pre-Hispanic peoples used oral language to influence the culture of their family and the community in which they lived. Similarly, Canciones que cuentan historias ('Songs that tell stories'), provides a sample of how people tell their stories through popular songs. Finally, a section called Mi comunidad también habla ('My community also speaks') is reserved especially for the learners. In it, they are encouraged to capture and recover oral traditions by writing down their own stories, recipes, advice, values, and perceptions about what is unique about their community.

In my Plazas classroom context, the types of activities as described above would often prompt discussions about learners' everyday lives and the range of reading demands placed on adults. More than once, learners brought in pieces of mail, as well as legal or healthcare-related documents to class and would ask for support in reading the contents in English and translating them to Spanish. As such, my facilitator role required me to wear multiple hats and adapt quickly to meet group and individual needs. Some learners required more individualised attention when it came to their reading development, which in turn necessitated a more adaptive teaching approach.

I will recall one example to illustrate a type of adaptive teaching practice involving reading aloud: a fellow facilitator had been using a written conversation strategy, or 'talking on paper' (Andrews, Beal and Corson 1990, 87), with a learner who had been struggling for some time to progress with reading beyond sounding out words. She wrote the following sentence in Spanish on the whiteboard (translated to English here): Hello, Roberto ${ }^{1}$. It's good to see you in class. I'm glad you came. He attempted to read the statement aloud several times. Suddenly, he began to cry. My colleague, preoccupied, asked him if he was okay; Roberto then replied that no one had ever written anything to him before (personal communication, K. Green, June

\footnotetext{
${ }^{1}$ Name has been changed for confidentiality purposes
} 
2019). This seemingly simple act of reading aloud to assist in general reading development (and in this case, words that were written to him) is just one example of many oral reading practices in adult learning contexts that remain unnoticed and insufficiently documented. First, this was an instance of reading aloud in a group (and therefore reading aloud as a shared experience) and in a safe space (within the Plazas classroom surrounded by fellow learners and facilitators). Additionally, it involved writing and reading notes aloud (in this instance, the facilitator writing to the learner) to communicate a message, with the added impact of a personalised meaning for the learner.

My exploration of the relationship between literacy and oracy and analysis of reading within the Plazas programme is limited by the scope of this study and by the fact that a targeted analysis of two modules and my reflections as a former facilitator are unable to capture or measure reading interactions that occur on a larger scale in adult literacy classrooms. However, there are a few key points to highlight: first, I suggest that reading aloud in the Plazas programme is used to help teach emergent reading by helping make the links between sound and symbols explicit, with the added value of engaging with a curriculum that takes into account the diverse life experiences of adult literacy learners (including, as we saw above, both engaging with a play and preparing for a community meeting). For Roberto, making that link between the sound and meaning of what was written to him seems to have marked a turning point in his overall literacy development. Second, it was my experience that different types of reading skills (and particularly different forms of oral reading) played a part in developing learner confidences outside of the classroom and extended beyond this to include wider social and cultural uses. For some of the learners in my classes, it meant acting out one of the plays featured in their Plazas books at the end of semester celebration; for others, it meant using their reading and writing skills to communicate with friends and family members in their home countries through text messages and email. Finally, while there have been studies that have explored the impact of oral language skills as a path to second language literacy and learning for adults (Condelli, Wrigley and Yoon 2009; Vinogradov and Bigelow 2010), further research that looks at the relationship between literacy and oracy in the context of L1 and L2 adult literacy classes (including different forms and uses of reading aloud) and explores the impact of different models of adult literacy learning could help to sustain programmes like Plazas both in the short- and long-term future.

\section{Community building}

Thinking about different ways to look at the relationship between oracy and literacy led me to consider another different (and I would argue equally important) dimension of the Plazas programme: reading about the world and linking this to learners' lives, sharing stories, and seeing learners develop their oral reading skills and confidences within and outside the classroom prompted me to think about how the Plazas programme carves out a distinct space for immigrant solidarity and community building. My present research related to indigenouslanguage literacy in different indigenous communities in Mexico has reinforced this notion: I observed how the U.S.-based Plazas where I worked and others in the same region acted as both spaces of learning and community resource hubs because they were housed in local organisations (including churches and schools) that catered directly to the local immigrant 
population. In contrast, many of the Plazas I encountered in Mexico served more as regional and administrative bases for local INEA chapters. Learning opportunities were often decentralised into local indigenous BLLP study circles in the more remote locations, many of which were severely constrained by limited resources and had fewer connections to other community resources or social institutions.

This led me to a wider observation about the different functions of literacy, particularly for immigrant groups: literacy can also act as a 'navigational technology' that opens up paths for understanding the complex and unfamiliar systems that many immigrants face in new countries (Vieira, 2013: 27). My time as a Plazas facilitator gave me insight into the challenges of learners living at the margins of U.S. society, and consequently, how the learners fostered a 'community of practice' (Lave and Wenger 1991) and drew from the literacy classes to establish important social and institutional connections and support networks in their wider communities. The importance of community building within the Plazas programme is further substantiated through data from surveys and interviews taken from Plazas in five major U.S. cities, where Délano Alonso (2018) found that many of those involved with the programme had been able to build networks, connect with their communities, and find solidarity with other immigrants. According to one programme coordinator, the programme 'gives [immigrants] tools to defend themselves, to avoid abuse, and to aspire to work in better places' (Délano Alonso 2018, 27). Perhaps the most salient finding from this research was the positive interactions with local institutions as a direct result of the Plazas programme. This notion aligns with Schmidtke's (2018) position that immigrants gain agency out of interactions with different community-based practices and institutions.

Finally, in my examination of the uses of reading aloud in Plazas sessions, I noted that reading aloud within both the printed materials and common tutor activities involves oral reading both to develop reading skills and as a way of meeting the varied reading practices important to learners in their everyday lives. Furthermore, this dynamic movement between reading and speaking often prompted multi-layered dialogues in the classroom that spoke to broader implications of what happens within the Plazas programme: it gives learners a space to connect the words in their textbooks back to their own experiences (or "reading the word") intertwined with a deeper critical engagement with their community and naming of these experiences (or "reading the world") (Freire and Macedo 1987). More generally, adult emergent literacy programmes with deep ties to the community such as Plazas have the potential to be a locus for increased access to key social institutions, in the U.S. and beyond. It is important that their conceptualisations and uses of literacy and oral language, in both L1 and L2, reflect how these communities meet social institutions. 


\section{Disclosure statement}

No potential conflict of interest was reported by the author.

\section{Notes on contributor}

Lorena Sanchez Tyson is a doctoral candidate in the Department of Education, Practice and Society at UCL Institute of Education. She holds a BA in English from the Universidad Autónoma de Tamaulipas (Mexico), and an MA in Lifelong Learning: Policy and Management from UCL (UK). Her doctoral research focuses on adult literacy in indigenous languages and contexts; other interests include lifelong learning, unschooling, and intercultural education.

\section{References}

Andrews, Paul Easton, Carole R. Beal, and John A. Corson. 1990. "Talking on Paper: Dialogue as a Writing Task for Sixth Graders." The Journal of Experimental Education 58 (2): 87-94.

Avila, Verdi N. 2007. “Tapping Into Mexican Resources To Educate Latinos.” American Association of School Administrators 64 (3): 48.

Belzer, Alisa. 2006. "What Are They Doing in There? Case Studies of Volunteer Tutors and Adult Literacy Learners." Journal of Adolescent \& Adult Literacy 49 (7): 560-72. https://doi.org/10.1598/jaal.49.7.2.

Brandt, Deborah. 2001. Literacy in American Lives. Cambridge University Press.

Brandt, Deborah, and Katie Clinton. 2002. "Limits of the Local: Expanding Perspectives on Literacy as a Social Practice." Journal of Literacy Research 34 (3): 337-56. http://journals.sagepub.com/doi/10.1207/s15548430jlr3403_4.

Como, L., and R.E. Snow. 1986. "Adapting Teaching to Individual Differences among Learners." In Handbook of Research on Teaching, edited by M. C. Wittrock, 605-29. New York: Macmillan.

Condelli, Larry, Heide Wrigley, and Kwan Suk Yoon. 2009. "“What Works' for Adult Students of English as a Second Language." In Tracking Adult Literacy and Numeracy Skills: Findings from Longitudinal Research, edited by Stephen Reder and John Bynner, 132-59. New York: Routledge.

Délano Alonso, Alexandra. 2018. "Integration through Ventanillas de Salud and Plazas Comunitarias." In From Here and There: Diaspora Policies, Integration, and Social Rights Beyond Borders. https://doi.org/10.1093/oso/9780190688578.001.0001.

Duncan, Sam, and Mark Freeman. 2019. "Adults Reading Aloud: A Survey of Contemporary Practices in Britain." British Journal of Educational Studies 0 (00): 1-27. https://doi.org/10.1080/00071005.2019.1610555.

Foorman, Barbara R. 1991. "Adult Literacy/Child Literacy: One World or Worlds Apart?" Linguistics and Education 3 (2): 103-8. https://doi.org/10.1016/0898-5898(91)90001-Y.

Freire, Paulo, and Donaldo Macedo. 1987. Literacy: Reading the Word and the World. London: Routledge.

Gee, James Paul. 2001. "Reading as Situated Language: A Sociocognitive Perspective." Journal of Adolescent \& Adult Literacy 44 (8): 714-25. https://doi.org/10.4324/9781315110592-7.

González Gutiérrez, Carlos. 2009. "The Institute of Mexicans Abroad: An Effort to Empower the Diaspora." In Closing the Distance: How Governments Strengthen Ties with Their Diasporas, edited by Dovelyn Rannveig Agunias. Washington, D.C.: Migration Policy Institute.

Hanemann, Ulrike. 2016. "Plazas Comunitarias, United States of America." 
https://uil.unesco.org/case-study/effective-practices-database-litbase-0/plazascomunitarias-united-states-america.

Hanemann, Ulrike, and Cassandra Scarpino. 2016. Literacy in Multilingual and Multicultural Contexts: Effective Approaches to Adult Learning and Education. UNESCO Institute for Lifelong Learning.

Hernández-Zamora, Gregorio. 2010. Decolonizing Literacy: Mexican Lives in the Era of Global Capitalism. Multilingual Matters Press.

INEA. n.d. (Instituto Nacional para la Educación de los Adultos). “Así Forjamos y Conservamos Nuestra Cultura." In Hablando Se Entiende La Gente. INEA. http://www.cursosinea.conevyt.org.mx/descargables/mevyt_pdfs/hablando/02_hablando antologia.pdf.

- n.d. "Community Plaza, Three Spaces for Life Education and Work." https://www.conevyt.org.mx/colaboracion/servicios/communityplaza2013.pdf.

_. n.d. "Cuando Las Voces Se Encuentran (CD)." Instituto Nacional para la Educación de los Adultos.

http://www.cursosinea.conevyt.org.mx/descargables/mevyt_pdfs/hablando/05_hablando _cd_cuadernillo.pdf.

${ }_{-}$-. n.d. "El Poder de La Palabra (Revista)." In Hablando Se Entiende La Gente. INEA. http://www.cursosinea.conevyt.org.mx/descargables/mevyt_pdfs/hablando/03_hablando _revista.pdf.

—_. n.d. "Hablando Se Entiende La Gente." INEA.

http://www.cursosinea.conevyt.org.mx/descargables/mevyt_pdfs/hablando/01_hablando libro.pdf.

- n.d. "Leer y Escribir." INEA.

http://www.cursosinea.conevyt.org.mx/descargables/mevyt_pdfs/leer_escribir/01_lye_li bro.pdf.

- 2015. "Evaluación Del Desempeño Plazas Comunitarias En Estados Unidos."

Jensen, Bryant, and Adam Sawyer. 2013. Regarding Educación: Mexican-American Schooling, Immigration, and Bi-National Improvement. Teachers College Press.

Laglagaron, Laureen. 2010. "Protection through Integration: The Mexican Government's Efforts to Aid Migrants in the United States.” Migration Policy Institute, 2010.

Lave, Jean, and Etienne Wenger. 1991. Situated Learning: Legitimate Peripheral Participation. Cambridge University Press.

Lytle, Susan L. 1991. "Living Literacy: Rethinking Development in Adulthood.” Linguistics and Education 3 (2): 109-38.

Moline, Emily Ariel. 2018. "L1 and L2 Adult Emergent Literacy: Reading Patterns, Oracy, and Interaction Within an English Literacy Program." University of California Davis.

Saal, Leah Katherine, and Margaret-Mary Sulentic Dowell. 2014. "A Literacy Lesson From an Adult 'Burgeoning' Reader." Journal of Adolescent and Adult Literacy 58 (2): 13545. https://doi.org/10.1002/jaal.325.

Schmidtke, Oliver. 2018. "The Civil Society Dynamic of Including and Empowering Refugees in Canada's Urban Centres." Social Inclusion 6 (1): 147-56. https://doi.org/10.17645/si.v6i1.1306.

Vieira, Kate. 2013. "On the Social Consequences of Literacy." Literacy in Composition Studies, 26-32.

http://licsjournal.org/OJS/index.php/LiCS/article/view/7/9\%0Ahttp://licsjournal.org/OJS /index.php/LiCS/article/view/136/189.

Vinogradov, Patsy, and Martha Bigelow. 2010. "Using Oral Language Skills to Build on the Emerging Literacy of Adult English Learners." CAELA Network Brief. https://doi.org/10.1260/136943303769013219. 
Wilkinson, Andrew. 1965. "The Concept of Oracy." Educational Review 17 (4): 11-15. https://doi.org/10.1111/j.1754-8845.1965.tb01326.x. 